\title{
Determination of Factors that Affect Time to Hospital Presentation in Patients with Symptoms Suggestive of an Acute Myocardial Infarction
}

CK Angus ${ }^{1}$, CAWalters ${ }^{2}$, NP Hart ${ }^{3}$, EW Williams ${ }^{4}$, RA Edwards ${ }^{4}$, JAWilliams-Johnson ${ }^{4}$

\author{
Affiliations: \\ the West Indies, Mona Campus, Jamaica. \\ Campus, Jamaica.

\section{Correspondence:} \\ Dr J Williams-Johnson \\ The Emergency Medicine Division \\ The Department of Surgery \\ Radiology, Anaesthetics and Intensive Care \\ The Faculty of Medical Sciences \\ The University of the West Indies \\ Kingston 7 Jamaica \\ Fax: +876 924-5471 \\ E-mail: jean.williamsjohnson@uwimona.edu.jm
}

${ }^{1}$ The Accident and Emergency Department, Spanish Town Hospital, St. Catherine. Jamaica.

${ }^{2}$ Research Section, The office of the Dean, The Faculty of Medical Sciences, The University of

${ }^{3}$ The Emergency Department, The King Edward VII Hospital, Bermuda.

${ }^{4}$ The Emergency Medicine Division, The Department of Surgery, Radiology, Anaesthetics and Intensive Care, The Faculty of Medical Sciences, The University of the West Indies, Mona

Short title: Time to Presentation with AMI symptoms to a University Hospital

Synopsis: Life saving measures for acute myocardial infarction include reperfusion therapy. There have been international studies done looking at factors contributing to prehospital delay in patients with such an event. This study looks factors that contribute to delays in a Jamaican University hospital population. 


\begin{abstract}
Objective: To determine the factors that affect time to hospital presentation in persons with symptoms suggestive of an acute myocardial infarction.

Methods: A cross-sectional study was done at the emergency department at the University Hospital of the West Indies, Kingston Jamaica. One hundred and fifty persons who presented with symptoms suggestive of an AMI and were later diagnosed as such were analyzed.
\end{abstract}

Results: Among the 150 patients, $52 \%$ of patients presented to the hospital 12 hours or later and $48 \%$ of patients presented earlier than 12 hours. A significant predictor of earlier presentation (odds ratio, \% CI) was fear of possible diagnosis $(0.50,0.25-0.99)$. Although not statistically significant, another factor associated with early presentation was persons with medical insurance $(0.41,0.19-0.87)$. None of the factors associated with delayed presentation 12 hours or later were found to be statistically significant, but were still deemed to be clinical important. These included elderly patients $(1.03,1.01-1.06)$, patients with prior stroke $(1.88,0.76-4.66)$ and patients with heart failure $(1.82,0.76-4.37)$.

Conclusion: Patients who have a myocardial infarction often delay in presenting to the hospital. This is a problem that many hospitals face globally and several factors have been found to be common among them. Educational programs targeting the study population and new strategies for easier access to health care facilities may be implemented so as to decrease prehospital times.

Keywords: Acute Myocardial Infarction, Delay in Hospital presentation, Fibrinolytic therapy 


\section{INTRODUCTION}

Acute myocardial infarction remains a leading cause of morbidity and mortality worldwide (1). Approximately 1.5 million cases of myocardial infarction occur annually in the United States (1). The prevalence of myocardial infarction (MI) in the Caribbean is unknown, early studies done in Trinidad and Tobago, Antigua and Barbuda and Bahamas show relatively high incidence (2). Myocardial infarction is defined as a clinical (or pathologic) event caused by myocardial ischemia in which there is evidence of myocardial injury or necrosis (3). Criteria are met when there is a rise and/or fall of cardiac biomarkers, along with supportive evidence in the form of typical symptoms, suggestive electrocardiographic (ECG) changes, or imaging evidence of new loss of viable myocardium or new regional wall motion abnormality (3). Risk factors that have been identified include hyperchloesterolemia, diabetes mellitus, hypertension, tobacco use, male gender, and family history of atherosclerotic arterial disease (4).

The typical symptoms of a MI include chest pain or discomfort that may radiate across the chest and to other areas of the body, including the upper abdomen, shoulders, arms, neck and throat, or lower jaw and teeth (5-6). The pain may come on suddenly or gradually and usually lasts for more than a few seconds. Of note, patients may present without a history of chest pain. (7). Patients presenting atypically are more likely to be older, diabetic, and female (8).

When patients who have symptoms suggestive of an MI present to the ED an ECG should be obtained within 10 minutes of arrival (9-10). Once the diagnosis of an MI is made, there is prompt initiation of therapy. The diagnosis needs to be made rapidly because the one year mortality risk is increased by $7.5 \%$ for each 30 minute delay in treatment (11-13). Acute myocardial infarction is associated with a $30 \%$ mortality rate; half of the deaths occur prior to arrival at the hospital. (13). 
Patients with symptoms of AMI often delay seeking medical care (11-13). Several studies worldwide have looked at various factors that contribute to delayed hospital presentation of these patients (14-17). This study however examined factors that might be indigenous to the Jamaican Emergency Department population and to compare these with international parameters, as information regarding this has not been documented previously. These would include variables such as the age of the patient, gender, presence of co-morbidities, educational level, and ignorance that presenting symptoms could be due to a life threatening illness. Once these are identified, public education can be instituted to target these factors in order to decrease the morbidity and mortality associated with AMI. The study therefore seeks to identify factors affecting the time to presentation to the emergency department (ED) in patients who have symptoms suggestive of an acute myocardial infarction (AMI).

\section{SUBJECTS AND METHODS}

This was a cross-sectional study of adult patients presenting with symptoms suggestive of an AMI which was later confirmed. The study period was from August 1, 2012 to December 31, 2012. The sample size was determined by using the prevalence of AMI over a three-month period with the desired confidence level at $95 \%$. The study was approved by the Ethics Committee of the University of the West Indies (UWI), Mona Campus. Time to presentation was initially coded as $<2$ hours, 2 to 12 and $>12$ hours. The cutoff of two hours from time of onset of symptoms to arrival at ED was chosen to characterize patients who sought medical attention in a timely fashion and for whom initiation of treatment would be of greatest benefit (18). The 12 hour time line was the cut off mark for administration of fibrinolytic therapy for those presenting with ST elevation 
MI (11). These cutoffs were also chosen because they were used in other studies. However due to the fact that only two patients presented before two hours, the results were merged and two new groups were formed, those patients presenting $\leq 12$ hours and those patients presenting $>12$ hours. The study was performed in the Emergency Medicine Division (EMD) the University Hospital of the West Indies, which is a large urban teaching hospital, located in the parish of Kingston. It is affiliated with the University of the West Indies. The EMD provides care for approximately 54,000 patients annually.

All patients over the age of 18 years who presented with symptoms suggestive of AMI and were diagnosed with AMI were included in the study. The diagnosis of AMI was made by the emergency physician when there was a rise and/or fall of cardiac biomarkers, along with suggestive electrocardiographic changes

Patients were excluded if they were cognitively impaired or had a recent history of trauma to the chest (within 72 hours).

\section{Measurements}

Eligible patients were then approached by trained study personnel (emergency physician residents and research assistants) and asked to participate in the study. The patients were allowed to review a research information sheet that briefly explained the study. Those that were willing to participate were asked to give a written consent and to complete a four page questionnaire which was administered by a research assistant. Also, if permission was granted by the patient, the relative of the patient was asked to complete the questionnaire on behalf of the patient. The questionnaire on average took approximately 20 minutes to complete and was completed at a time that was appropriate (i.e., once the patient had been stabilized and was clinically well enough to complete 
such a task). The information collected included patient demographics (age, gender, highest educational level and employment status), medical insurance, medical and social history of the patient and patient disposition (whether discharged home, admitted or deceased). Data was also collected about the symptoms felt and the time between symptom onset and hospital presentation. Upon completion of the questionnaire, it was placed in a drop box in the EMD. All data collected were coded and uploaded to a password-protected database; any identifying information was delinked and kept separately from the main data fields.

\section{Statistical analysis}

In accordance with the primary objective of this study, the statistical analysis was descriptive. Data was entered in and analyzed using the SSPS version 16.0. Chi squared tests were used to compare time to presentation with categorical variables and those that were deemed statistically significant were evaluated for independent associations in a logistic regression model.

\section{RESULTS}

A total of 150 patients with documented AMI were enrolled in the study. There were nearly an equal proportion of men and women $(57.3 \%$ men $)$. The median age was 59.5 years for the 12 hours and less group and 66 years for the 12 hours and over group. Of note, there was significant deviation from normality for the age distribution particularly within the "over 12" group. As a result of this deviation, it was more accurate to report median (IQR) age and use the non-parametric Wilcoxon rank sum test to compare median ages between the "12 \& under" and "over 12" groups. See Figures 1 and 2. 
The prevalence of hypertension (91.3\%) and diabetes $(41.3 \%)$ were high and $21.3 \%$ of patients had a history of heart failure. Twenty percent of patients were previously diagnosed with a stroke while $15.3 \%$ had a history of a prior myocardial infarction. Twenty two percent of patients had a prior history of angina and $4.7 \%$ of them admitted to a current history of smoking.

In the study population, $48 \%$ of patients presented within 12 hours or less of symptom onset while $52 \%$ percent presented 12 hours or after. When using univariate analyses, several significant differences were seen among the two groups. See Table 1. Elderly patients (median age 66 years) were more likely to present 12 hours or later compared to the younger age group. In addition to this patients with a history of heart failure (28.2\%) and prior stroke (26.9\%) were found to take longer than 12 hours to seek medical attention after symptom onset than those without such a history. There were almost an equal number of patients presenting within 12 hours with a history of angina (23.9\%) when compared to those presenting 12 hours and after (20. 3\%). This was also true for patients with a prior history of stroke with $18.1 \%$ of them presenting before 12 hours and $12.8 \%$ of them presenting 12 hours and after. Patients who did not have medical insurance $(33.3 \%)$ and those who earned less than $\$ 5000 /$ week (44.9\%) also delayed 12 hours or longer in presenting to the ED.

When looking at the two groups, the reasons affecting time to presentation that were statistically significant included fear of possible diagnosis and financial constraint. However patients that feared the diagnosis $(34.3 \%)$ presented 12 hours or earlier while those with financial constraint $(20.5 \%)$ were found to present 12 hours or later. Of note, unavailability of transportation almost reached statistical significance with $14.1 \%$ of patients reporting it as a reason for delay in seeking medical attention. Of statistical significance was employment status, for it was found that of the persons who were employed (62.5\%) sought medical attention 12 hours or less while those 
who were unemployed (26.9\%), pensioners (21.8\%) and self-employed (12.8\%) took 12 hours or longer to present to hospital for medical care. It was noted that $18 \%$ of patients who live alone presented to the hospital within 12 hours and $26 \%$ of them delayed greater than 12 hours or longer but this was not found to be statistically significant. The same was true for patients with different educational backgrounds. There were no significance differences between the three groups as 16.8 $\%$ of those who only achieved primary education, $61.5 \%$ attaining secondary education and 21.8 $\%$ achieving up to a tertiary education presented to the hospital 12 hours or later.

To identify factors that might be individual predictors of hospital presentation time, a logistic regression was done with the dependent variable, dichotomized as less than 12 hours and 12 hours or greater. All statistically significant categorical variables based on the chi - squared tests of association were introduced into the model. Income less than $\$ 5000 / \mathrm{wk}$ and unemployment were used as the reference groups in the corresponding categorical variables. Independent differences in time to presentation between the each reference group and their associated groups were then done. See Table 2.

The results of the analysis showed that older patients, history of heart failure, patients with financial constraint and pensioners were more likely to present later than 12 hours. On the other hand patients with medical insurance, those who earned greater than $\$ 20,000 /$ wk, patients who were employed and those who were fearful of the diagnosis presented 12 hour or earlier to the hospital. When controlling for age, shown in model one, financial constraint, history of heart failure and prior stroke were still associated with increased likelihood of presenting later than 12 hours to the hospital. Also retaining significance were patients with medical insurance, those whose income was greater than $\$ 20.000 /$ wk and those who feared the diagnosis, as these patients presented 12 hours or earlier to the hospital. In model 2, we examined all the variables controlling 
for the effect of each of the factors. However income was excluded due to uncertainty of the validity of the data and employment status was exclude because it was not statistically significant in model 1. Fear of diagnosis was the only variable found to be significant where a half of the likelihood of presenting later than 12 hours post symptom onset.

\section{DISCUSSION}

Early administration of a fibrinolytic agent reduces infarct size and improves survival $(11,19)$. The survival benefit is greatest when fibrinolytic agents are administered within the first four hours after the onset of symptoms and particularly within the first 60 minutes (18). The benefit from fibrinolytic therapy declines rapidly thereafter and after twelve hours the benefit may not exceed the risk (11). This analysis demonstrated that demographic and socioeconomic factors are associated with time to presentation. Other factors that affected presentation time included medical history and emotional reasons.

Though the final outcome only showed that fear of diagnosis was statistically significant, when all other variables were controlled for, the study still brought out several clinically important factors.

Prior studies done indicate that up to $40 \%$ of AMI arrive after 6 hours (20). This is even more marked in persons who present later than 6 hours. In our study over half of the patients presented after 12 hours, when the potential benefit from fibrinolytic therapy is much reduced. It is well established that older persons take longer to access medical care than younger persons and this has been supported by the findings in our study (14, 20-21). Clear reasons for more prolonged delay in seeking hospital treatment among this age group are unknown; however 
possible explanations include the atypical presentations of AMI, negative previous hospital experiences and limited access to health care $(15,22-23)$.

In our study persons with a history of heart failure were found to take longer to present to hospital than those without heart failure. It is unclear why patients with a history of heart failure should take longer to present to hospital after symptom onset for it is well known that heart failure complicating acute myocardial infarction is associated with a worse prognosis (24).

Income and employment status were also significant. Although there has been limited data looking directly at income and employment status as factors that were associated with delayed hospital presentation, some studies have suggested that time to presentation is longer in patients with low socioeconomic status $(23,25-26)$. Employed patients and patients with medical insurance were found to present to the hospital earlier. However some studies show that lack of medical insurance has no effect on hospital presentation time (27).

Despite previous studies showing that women suspected of having an AMI were more likely to present later to hospital than men, there was no association observed in our study between gender and time to presentation $(20,26,28)$. In previous studies done persons with diabetes were shown to present later to the hospital, possibly due to the associated complication of diabetic neuropathy that would alter perception of myocardial ischemia $(26,28)$. However this was not seen in the study as there was an almost equal amount of diabetic patients presenting within each time period. This only emphasizes the need for more public education, so as to inform persons of the increased risks of cardiovascular events associated with diabetes mellitus.

Additionally history of cardiac risk factors or cardiac disease (including hypercholesterolemia, history of angina or myocardial infarction) showed no significant difference with regards to time to hospital presentation between the two groups. This is not the case in 
previous studies have showed a patients with prior angina delay in presentation to the hospital (29). On the other hand histories of prior infarction and high cholesterol has had inconsistent associations in previous studies (23).

Time to presentation has been shown to be affected by several cognitive and emotional factors such as attribution of symptoms to other preexisting conditions, fear of embarrassment should symptoms turn out to be benign and waiting to see if symptoms would resolve on their own $(16,30-32)$. This was not found in our study, however it was interesting to note that persons with a fear of the possible diagnosis of AMI presented earlier. Although it has not been investigated extensively, prior studies have shown no significance relating fear of possible diagnosis with hospital presentation time $(17,33)$.

One limitation was that a question that should have been asked was whether or not persons were aware of the symptoms of a heart attack. This is of particular importance, for if patients are informed about the typical symptoms of an acute myocardial infarction, and still delay in seeking medical attention then it would serve to reinforce the need to educate them about the red flags for life threatening condition. Notwithstanding this, patient time to hospital presentation was affected by a fear of the possible diagnosis.

Another major limitation was that the comparison of shorter time intervals with the different independent variables may have been better to analyze instead of presentation 12 hours or less and greater than 12 hours. This would have also allowed for easier comparison with other studies that used shorter time intervals.

Other limitations included the use of a single institution as the study population and relying on patients or relatives to recall their symptoms and the events surrounding it. This was also done at a time of high stress, which could have magnified inaccuracy. 


\section{CONCLUSION}

This was the first local study that sought to look at factors that determined time to hospital presentation in patients who had symptoms suggestive of an AMI. It should also be noted that time was not treated as a continuous variable in the study so this work does not examine all the determinants of time of presentation but merely those that contribute to whether or not patients present beyond the time when reperfusion is likely to be of benefit.

Although many associations were not found to be statistically significant, a few were considered clinically meaningful and deductions could still be made regarding future recommendations. Some of these clinically significant associations included the fact that elderly persons, persons with financial constraint, persons with a heart failure and persons with a prior history of stroke took longer to present to the hospital after symptom onset. Therefore continuous educational efforts should be made targeting these identified groups of persons and the public on the diverse ways in which an AMI may present, emphasizing the importance of early recognition and the benefit to seeking early treatment.

This research initiative could be expanded to involve a larger study population e.g. inclusion of other hospitals across the country. The development of sustained health promotion and education programs as well as the introduction of new strategies for easier access to healthcare facilities may result in persons with symptoms of AMI presenting earlier to hospital. 


\section{ACKNOWLEDGEMENTS}

The authors wish to thank the Emergency Medicine Division UHWI for having allowed the use of the facility for the study.

\section{AUTHORS’ NOTE}

CK Angus and JA Williams Johnson conceived the paper, participated in study design and oversaw data collection. CA Angus wrote the manuscript. JA Williams Johnson, EW Williams, N. Hart and R. Edwards, critically revised the manuscript and approved final version. CA Walters participated in data analysis and interpretation and provided statistical oversight for the paper and approved final version. The authors declare they have no conflicts of interest. 


\section{REFERENCES}

1. Rosamond W, Flegal K, Furie K, Go A, Greenlund K, Haase N, et al. Heart disease and stroke statistics--2008 update: a report from the American Heart Association Statistics Committee and Stroke Statistics Subcommittee. Circulation. 2008 Jan 29;117(4):e25-146.

2. Martin T. Acute myocardial infarction in the West Indies early observations, current issues and future concerns. West Indian Med. J. 2009;58:546-50.

3. Thygesen K, Alpert JS, Jaffe AS, White HD. Diagnostic application of the universal definition of myocardial infarction in the intensive care unit. Curr Opin Crit Care. 2008 Oct;14(5):543-8.

4. Yusuf S, Hawken S, Ounpuu S, Dans T, Avezum A, Lanas F, et al. Effect of potentially modifiable risk factors associated with myocardial infarction in 52 countries (the INTERHEART study): case-control study. Lancet. 2004 Sep 11-17;364(9438):937-52.

5. Swap CJ, Nagurney JT. Value and limitations of chest pain history in the evaluation of patients with suspected acute coronary syndromes. JAMA. 2005 Nov 23;294(20):2623-9.

6. Berger JP, Buclin T, Haller E, Van Melle G, Yersin B. Right arm involvement and pain extension can help to differentiate coronary diseases from chest pain of other origin: a prospective emergency ward study of 278 consecutive patients admitted for chest pain. $\mathbf{J}$ Intern Med. 1990 Mar;227(3):165-72.

7. Canto JG, Shlipak MG, Rogers WJ, Malmgren JA, Frederick PD, Lambrew CT, et al. Prevalence, clinical characteristics, and mortality among patients with myocardial infarction presenting without chest pain. JAMA. 2000 Jun 28;283(24):3223-9. 
8. Canto AJ, Kiefe CI, Goldberg RJ, Rogers WJ, Peterson ED, Wenger NK, et al. Differences in symptom presentation and hospital mortality according to type of acute myocardial infarction. Am Heart J. 2012 Apr;163(4):572-9.

9. Diercks DB, Kirk JD, Lindsell CJ, Pollack Jr CV, Hoekstra JW, Gibler WB, et al. Doorto-ECG time in patients with chest pain presenting to the ED. Am J Emerg Med. [doi: 10.1016/j.ajem.2005.05.016]. 2006;24(1):1-7.

10. Zègre-Hemsey J, Sommargren CE, Drew BJ. Initial ECG Acquisition Within 10 Minutes of Arrival at the Emergency Department in Persons With Chest Pain: Time and Gender Differences. J Emerg Nurs. 2011;37(1):109-12.

11. Indications for fibrinolytic therapy in suspected acute myocardial infarction: collaborative overview of early mortality and major morbidity results from all randomised trials of more than 1000 patients. Fibrinolytic Therapy Trialists' (FTT) Collaborative Group. Lancet. 1994;343(8893):311-22.

12. Berger PB, Ellis SG, Holmes DR, Jr., Granger CB, Criger DA, Betriu A, et al. Relationship between delay in performing direct coronary angioplasty and early clinical outcome in patients with acute myocardial infarction: results from the global use of strategies to open occluded arteries in Acute Coronary Syndromes (GUSTO-IIb) trial. Circulation. 1999 Jul 6;100(1):14-20.

13. Berger PB, Tuttle RH, Holmes DR, Jr., Topol EJ, Aylward PE, Horgan JH, et al. One-year survival among patients with acute myocardial infarction complicated by cardiogenic shock, and its relation to early revascularization: results from the GUSTO-I trial. Circulation. 1999 Feb 23;99(7):873-8. 
14. Goff DC, Jr., Feldman HA, McGovern PG, Goldberg RJ, Simons-Morton DG, Cornell CE, et al. Prehospital delay in patients hospitalized with heart attack symptoms in the United States: the REACT trial. Rapid Early Action for Coronary Treatment (REACT) Study Group. Am Heart J. 1999 Dec;138(6 Pt 1):1046-57.

15. Goldberg RJ, Yarzebski J, Lessard D, Gore JM. Decade-long trends and factors associated with time to hospital presentation in patients with acute myocardial infarction: the Worcester Heart Attack study. Arch Intern Med. 2000 Nov 27;160(21):3217-23.

16. Dracup K, McKinley SM, Moser DK. Australian patients' delay in response to heart attack symptoms. Med J Aust. 1997 Mar 3;166(5):233-6.

17. McKinley S, Dracup K, Moser DK, Ball C, Yamasaki K, Kim CJ, et al. International comparison of factors associated with delay in presentation for AMI treatment. Eur J Cardiovasc Nurs. 2004 Sep;3(3):225-30.

18. Boersma E, Maas AC, Deckers JW, Simoons ML. Early thrombolytic treatment in acute myocardial infarction: reappraisal of the golden hour. Lancet. 1996 Sep 21;348(9030):7715.

19. Chareonthaitawee P, Gibbons RJ, Roberts RS, Christian TF, Burns R, Yusuf S. The impact of time to thrombolytic treatment on outcome in patients with acute myocardial infarction. For the CORE investigators (Collaborative Organisation for RheothRx Evaluation). Heart. 2000 Aug;84(2):142-8.

20. Gurwitz JH, McLaughlin TJ, Willison DJ, Guadagnoli E, Hauptman PJ, Gao X, et al. Delayed hospital presentation in patients who have had acute myocardial infarction. Ann Intern Med. 1997 Apr 15;126(8):593-9. 
21. Grossman SA, Brown DFM, Chang Y, Chung WG, Cranmer H, Dan L, et al. Predictors of delay in presentation to the ED in patients with suspected acute coronary syndromes. Am J Emerg Med. 2003;21(5):425-8.

22. Goldberg RJ, Spencer FA, Fox KA, Brieger D, Steg PG, Gurfinkel E, et al. Prehospital Delay in Patients With Acute Coronary Syndromes (from the Global Registry of Acute Coronary Events [GRACE]). Am J Cardiol. 2009 Mar 1;103(5):598-603.

23. Dracup K, Moser DK, Eisenberg M, Meischke H, Alonzo AA, Braslow A. Causes of delay in seeking treatment for heart attack symptoms. Soc Sci Med. 1995 Feb;40(3):379-92.

24. Wu AH, Parsons L, Every NR, Bates ER. Hospital outcomes in patients presenting with congestive heart failure complicating acute myocardial infarction: a report from the Second National Registry of Myocardial Infarction (NRMI-2). J Am Coll Cardiol. 2002 Oct $16 ; 40(8): 1389-94$.

25. Sheifer SE, Rathore SS, Gersh BJ, Weinfurt KP, Oetgen WJ, Breall JA, et al. Time to presentation with acute myocardial infarction in the elderly: associations with race, sex, and socioeconomic characteristics. Circulation. 2000 Oct 3;102(14):1651-6.

26. Yarzebski J, Goldberg RJ, Gore JM, Alpert JS. Temporal trends and factors associated with extent of delay to hospital arrival in patients with acute myocardial infarction: the Worcester Heart Attack Study. Am Heart J. 1994 Aug;128(2):255-63.

27. Novak K, Aljinovic J, Kostic S, Capkun V, Novak Ribicic K, Batinic T, et al. Pain to hospital times after myocardial infarction in patients from Dalmatian mainland and islands, southern Croatia. Croat Med J. 2010 Oct;51(5):423-31. 
28. Newby LK, Rutsch WR, Califf RM, Simoons ML, Aylward PE, Armstrong PW, et al. Time from symptom onset to treatment and outcomes after thrombolytic therapy. GUSTO-1 Investigators. J Am Coll Cardiol. 1996 Jun;27(7):1646-55.

29. Meischke H, Eisenberg MS, Larsen MP. Prehospital delay interval for patients who use emergency medical services: the effect of heart-related medical conditions and demographic variables. Ann Emerg Med. 1993 Oct;22(10):1597-601.

30. McKinley S, Moser DK, Dracup K. Treatment-seeking behavior for acute myocardial infarction symptoms in North America and Australia. Heart Lung. 2000 JulAug;29(4):237-47.

31. Leslie WS, Urie A, Hooper J, Morrison CE. Delay in calling for help during myocardial infarction: reasons for the delay and subsequent pattern of accessing care. Heart. 2000 Aug;84(2):137-41.

32. Rucker D, Brennan T, Burstin H. Delay in seeking emergency care. Acad Emerg Med. $2001 \mathrm{Feb} ; 8(2): 163-9$.

33. Luepker RV, Raczynski JM, Osganian S, Goldberg RJ, Finnegan JR, Jr., Hedges JR, et al. Effect of a community intervention on patient delay and emergency medical service use in acute coronary heart disease: The Rapid Early Action for Coronary Treatment (REACT) Trial. JAMA. 2000 Jul 5;284(1):60-7. 
Table 1: Characteristics of patients presenting in $\leq 12 \mathrm{hrs}$ and $>12 \mathrm{hrs}$ after onset of chest pain

\begin{tabular}{|c|c|c|c|}
\hline Characteristic & $\leq 12 \mathrm{hrs}$ & $>12 \mathrm{rs}$ & $\mathrm{P}$ \\
\hline $\mathrm{n}(\%)$ & 72 & 78 & \\
\hline \multicolumn{4}{|l|}{ Demographic variables } \\
\hline Median age (IQR) & $59.5(42.5-68)$ & $66.0(58-72)$ & 0.003 \\
\hline Male $(\%)$ & $45(62.5)$ & $41(52.6)$ & 0.219 \\
\hline \multicolumn{4}{|l|}{ Cardiac history variables } \\
\hline Prior MI \% & $13(18.1)$ & $10(12.8)$ & 0.374 \\
\hline Prior stroke \% & $9(12.5)$ & $21(26.9)$ & 0.027 \\
\hline $\begin{array}{l}\text { History of angina } \% \\
\text { History of heart failure } \%\end{array}$ & $17(23.9)$ & $16(20.5)$ & 0.614 \\
\hline Other clinical variables & $10(13.9)$ & $22(28.2)$ & 0.032 \\
\hline \multicolumn{4}{|l|}{ Hypertension \% } \\
\hline Diabetes \% & $67(93.1)$ & $70(89.7)$ & 0.471 \\
\hline Hypercholesterolemia (\%) & $28(38.9)$ & $34(41.3)$ & 0.559 \\
\hline Currently smoking $(\%)$ & $33(45.8)$ & $46(59.0)$ & 0.107 \\
\hline \multirow{2}{*}{\multicolumn{4}{|c|}{$\begin{array}{l}\text { Factors associated with time to presentation } \\
\text { Unsure of possible diagnosis }(\%)\end{array}$}} \\
\hline & & & \\
\hline Attempted other means of treatment (\%) & $16(22.9)$ & $20(25.6)$ & 0.693 \\
\hline No transportation $(\%)$ & $19(27.1)$ & $21(26.9)$ & 0.976 \\
\hline Fear of possible diagnosis $(\%)$ & $4(5.7)$ & $16(20.5)$ & 0.009 \\
\hline Embarrassed to ask for help (\%) & $4(5.7)$ & $11(14.1)$ & 0.091 \\
\hline Waiting to see if symptoms resolved (\%) & $24(34.3)$ & $14(17.9)$ & 0.023 \\
\hline Did not have anyone to ask for help (\%) & $6(8.6)$ & $4(5.1)$ & 0.405 \\
\hline Called/went to see private doctor $(\%)$ & $18(25.7)$ & $16(20.5)$ & 0.453 \\
\hline Those with medical insurance (\%) & $1(1.4)$ & $5(6.4)$ & 0.125 \\
\hline Income(\$/week) & $10(14.3)$ & $9(11.5)$ & 0.618 \\
\hline \multicolumn{4}{|l|}{ Less than $5,000(\%)$} \\
\hline 5,000 to $20,000(\%)$ & $43(59.7)$ & $26(33.3)$ & 0.001 \\
\hline \multirow[t]{2}{*}{ Those that live alone (\%) } & $16(22.2)$ & $35(44.9)$ & 0.007 \\
\hline & $17(23.6)$ & $18(23.1)$ & \\
\hline \multicolumn{4}{|l|}{ Employment status } \\
\hline $\begin{array}{l}\text { Self employed (\%) } \\
\text { Employed (\%) } \\
\text { Unemployed (\%) }\end{array}$ & $18(25.0)$ & $26(33.3)$ & 0.263 \\
\hline Pensioners $(\%)$ & $8(11.1)$ & & רב000 \\
\hline Educational level & $45(62.5)$ & $\begin{array}{l}10(12.8) \\
30(38.5)\end{array}$ & 0.022 \\
\hline Primary $(\%)$ & $12(16.7)$ & $21(26.9)$ & \\
\hline \multirow[t]{4}{*}{ Tertiary $(\%)$} & $7(9.7)$ & $17(21.8)$ & \\
\hline & $6(8.33)$ & $13(16.8)$ & 0.206 \\
\hline & $44(61.1)$ & $48(61.5)$ & \\
\hline & $22(30.6)$ & $17(21.8)$ & \\
\hline
\end{tabular}


Table 2: Results of binary logistic regression analysis of independent predictors of time to hospital presentation.

\begin{tabular}{|c|c|c|c|}
\hline \multirow[t]{2}{*}{ Characteristic } & \multirow[t]{2}{*}{$\begin{array}{l}\text { Unadjusted OR } \\
(95 \% \mathrm{CI})\end{array}$} & $\begin{array}{l}\text { Adjusted OR } \\
\text { (95\% CI })\end{array}$ & \multirow{2}{*}{$\begin{array}{c}\text { Adjusted OR } \\
\qquad \begin{array}{c}(95 \% \text { CI }) \\
\text { Model } 2\end{array}\end{array}$} \\
\hline & & Model 1 & \\
\hline Specific age & $1.03(1.01-1.06)^{*}$ & - & $1.02(0.99-1.05)$ \\
\hline Prior stroke & $2.58(1.09-6.08)$ & $1.88(0.76-4.66)^{*}$ & $1.66(0.64-4.30)$ \\
\hline $\mathrm{HF}$ & $2.44(1.06-5.59)^{*}$ & $1.82(0.76-4.37)^{*}$ & $1.43(0.58--3.56)$ \\
\hline Medical insurance & $0.32(0.16-0.62)^{*}$ & $0.41(0.19-0.87)^{*}$ & $0.58(0.26-1.32)$ \\
\hline Financial constraint & $4.26(1.43-13.4)^{*}$ & $3.52(1.09-11.4)^{*}$ & $2.19(0.63-7.60)$ \\
\hline Fear of diagnosis & $0.42(0.20-0.90)^{*}$ & $0.46(0.21-0.99)^{*}$ & $0.50(0.25-0.99)^{*}$ \\
\hline \multicolumn{4}{|l|}{ Income (\$/wk) } \\
\hline $5,000-20,000$ & $0.43(0.18-1.04)$ & $0.49(0.18-1.04)$ & - \\
\hline Greater than 20,000 & $0.27(0.13-0.60)^{*}$ & $0.37(0.13-0.60)^{*}$ & - \\
\hline Self employment & $0.71(0.22-2.30)$ & $0.89(0.26-3.01)$ & - \\
\hline Employed & $0.38(0.16-0.89)^{*}$ & $0.51(0.20-1.29)$ & - \\
\hline Pensioners & $1.39(0.45-4.30)$ & $1.30(0.41-4.05)$ & - \\
\hline
\end{tabular}

Odds ratio (OR) greater than 1.0 indicates that the factor of interest is associated with arrival to hospital greater than $12 \mathrm{hrs}$. CI indicates confidence interval. * $\mathrm{p}<0.05$ 


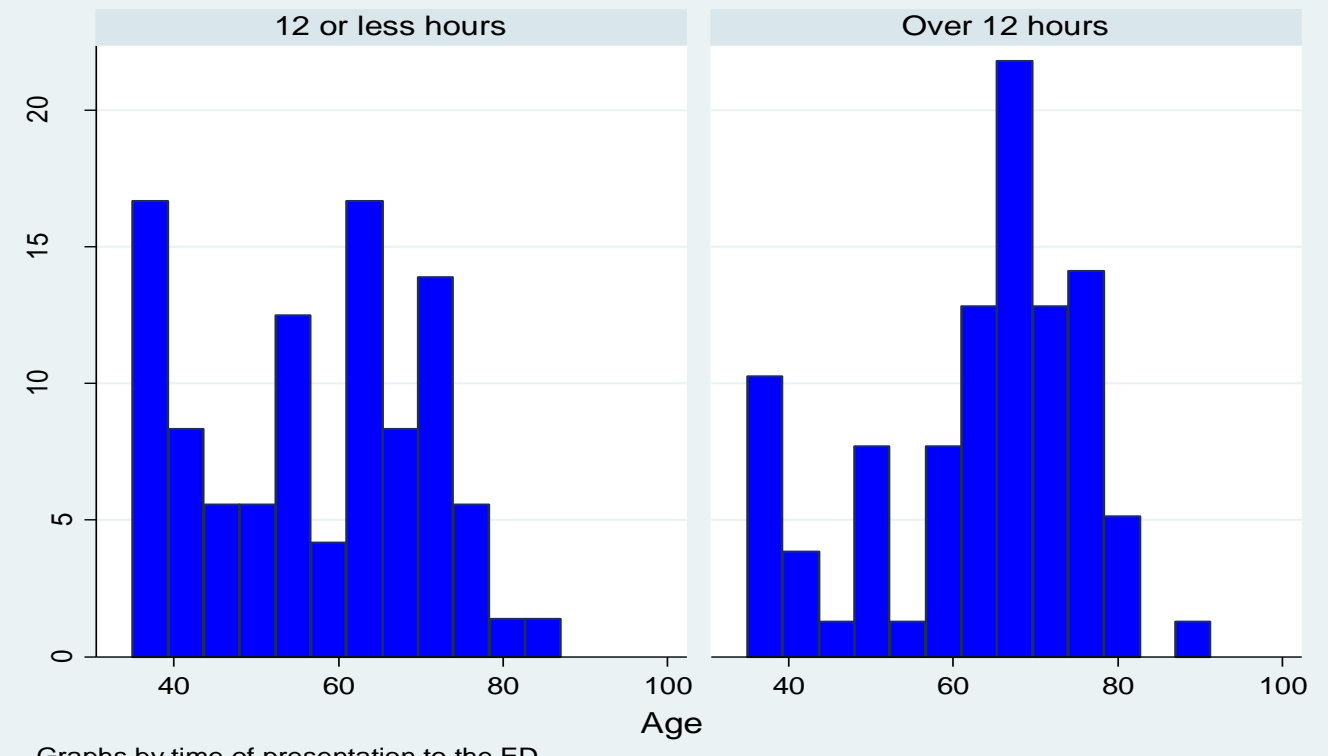

Fig. 1: Age distribution according to time to hospital presentation. 